\title{
CLASSE HOSPITALAR: A ARTICULAÇÃO DA SAÚDE E EDUCAÇÃO COMO EXPRESSÃO DA POLÍTICA DE HUMANIZAÇÃO DO SUS
}

\author{
HOSPITAL CLASS: COORDINATION BETWEEN HEALTH AND EDUCATION AS AN EXPRESSION \\ OF THE NHS' POLICY OF HUMANIZATION
}

\author{
Edson Vanderlei Zombini ${ }^{1}$ \\ Cláudia Maria Bogus ${ }^{2}$ \\ Isabel Maria Teixeira Bicudo Pereira ${ }^{3}$ \\ Maria Cecília Focesi Pelicioni ${ }^{4}$
}

Resumo A saúde é determinada por condições sociais, econômicas, educacionais, políticas e ambientais, extrapolando, portanto, a dimensão exclusivamente biológica. O presente trabalho tenta estabelecer uma reflexão interpretativa sobre os princípios do SUS e mostrar a interface deles com a proposta da classe hospitalar, uma modalidade de educação especial que estimula a construção de conhecimentos, a capacitação e o ensino de algumas habilidades, contribuindo para o desenvolvimento infantil. Trata-se de um exercício de argumentação para o entendimento do papel da classe hospitalar na realização da atenção integral à saúde no Brasil. O desenvolvimento de atividades pedagógico-educacionais em hospitais permite oferecer às crianças e adolescentes hospitalizados a continuidade do seu aprendizado.

Palavras-chave promoção da saúde; humanização; classe hospitalar; educação; SUS.
Abstract Health is determined by social, economic, educational, political and environmental conditions and, as such, it ranges well beyond a solely biological dimension. This article attempts to establish an interpretative reflection on the principles of the NHS and to show the interface of such principles with the hospital class proposal, a type of special education that encourages the construction of knowledge, training and the teaching of a set of skills to contribute to development in childhood. This is an exercise of reasoning conceived to understand the role played by the hospital class in the achievement of comprehensive health care in Brazil. Providing educational activities in hospitals allows hospitalized children and adolescents to carry on with their learning processes.

Keywords health promotion; humanization; hospital class; education; NHS. 


\section{Introdução}

A saúde é essencial à qualidade de vida e deve ser vivenciada no cotidiano. É determinada por condições sociais, econômicas, educacionais, políticas e ambientais, extrapolando a dimensão exclusivamente biológica. Uma nova cultura do cuidado na atenção à saúde, adotada desde a implantação da Política Nacional de Humanização em Saúde, em 2003, tem aliado a qualidade técnica ao reconhecimento da singularidade e integralidade, buscando assim o resgate da cidadania dos indivíduos (Brasil, 2004).

No âmbito hospitalar, muitas iniciativas vêm sendo efetivadas nesse sentido: organização de grupos de discussão de problemas do dia a dia hospitalar, com a participação de profissionais da equipe da saúde e dos usuários; criação de ouvidorias visando dar voz ao usuário para reivindicação de melhorias do serviço e garantir os seus direitos; estímulo às equipes de saúde para informar sobre os vários aspectos da enfermidade, do tratamento ao prognóstico; reforço à família e aos acompanhantes para que possam participar ativamente na recuperação do paciente; prolongamento do horário de visitas; direito de acompanhamento familiar de doentes idosos e crianças; incentivo ao lazer, por meio de brinquedotecas e da presença de contadores de história; e terapia por meio de música, artistas, palhaços e animais. Tais ações têm o propósito de amenizar os efeitos negativos - físicos, emocionais e sociais - da internação e garantir o respeito e a cidadania dos indivíduos.

Nos hospitais destinados à atenção de crianças e adolescentes, além das atividades humanizadoras existentes, outros esforços vêm sendo empreendidos para a criação de ambientes destinados ao atendimento pedagógicoeducacional, que permitam a continuidade do desenvolvimento cognitivo e educacional dos pacientes durante o período de hospitalização. Nesse sentido, destaca-se a classe hospitalar, cujas diretrizes foram estabelecidas pelo $\mathrm{Mi}$ nistério da Educação e Cultura, em 2001 (Brasil, 2001).

Os primórdios da intervenção escolar em hospitais datam de 1935, na França. No Brasil, a primeira ação educativa escolar durante a hospitalização surgiu na década de 1950, no Rio de Janeiro, no Hospital Municipal Jesus.

A Sociedade Brasileira de Pediatria (2001) tem referendado, dentre os direitos da criança e do adolescente hospitalizados, o direito de as crianças desfrutarem de programas de educação em saúde e acompanhamento do currículo escolar. Porém, atualmente, apesar do aumento do número de classes hospitalares nas várias unidades federativas, a grande maioria dos hospitais do país ainda não possui atendimento pedagógico para o escolar hospitalizado.

Cabe às classes hospitalares a elaboração de estratégias pedagógico-educacionais que possibilitem o acompanhamento curricular do aluno enquanto estiver hospitalizado, garantam a manutenção do vínculo escolar e deem 
continuidade ao processo de desenvolvimento e à construção do conhecimento no âmbito da educação básica, favorecendo o seu ingresso ou retorno ao ensino regular (Fonseca, 2003).

Durante décadas, crianças e adolescentes hospitalizados eram tratados como sujeitos sem direitos e necessidades, inclusive sem direito à educação, e, na maioria das vezes, afastados da escola e do ensino nos períodos de internação ou de impossibilidade física de frequência à escola (De Paula e Matos, 2007).

$\mathrm{O}$ ambiente hospitalar em geral traz diferentes angústias: além do desconforto físico que a própria doença produz, as crianças, ao entrarem em contato com um ambiente estranho e com pessoas desconhecidas, e ao serem submetidas a procedimentos diagnósticos e terapêuticos muitas vezes dolorosos, podem desenvolver distúrbios emocionais e do sono, regressão, insegurança e depressão (Monteiro, 2007).

Tem se verificado que atividades educativas durante a internação reduzem a ansiedade inerente à hospitalização, minimizando a dor, o medo e a desconfiança, além de darem oportunidade à criança de atualizar suas necessidades cognitivas e desvincular-se, mesmo que momentaneamente, das restrições que o tratamento hospitalar impõe. Essas atividades fazem as crianças sentirem-se menos doentes e amenizam a sensação de perda temporária da vida cotidiana (Fonseca, 2003).

A permanência da criança no hospital não deve representar o rompimento de seu vínculo com a escola e a perda do direito à escolarização. As classes hospitalares garantem às crianças e adolescentes hospitalizados a oportunidade de continuarem a vivenciar as experiências pedagógicas. Além da garantia do contato com o saber, que estimula o processo cognitivo e de desenvolvimento, elas implicam a continuidade das relações interpessoais.

Devido ao contato diário com o paciente e seus familiares, o professor da classe hospitalar auxilia nas interações com a equipe de saúde, sendo capaz de, pela observação em sala de aula, identificar padrões de comportamento até então não percebidos pela equipe.

O professor da classe hospitalar deve articular-se com a equipe de saúde do hospital, com a Secretaria de Educação e com a escola de origem do educando, colaborando, assim, na atenção ao restabelecimento da saúde e garantindo, por meio do cumprimento da grade curricular, a continuidade do aprendizado e a aprovação da criança para o próximo ano escolar.

Ainda que os pressupostos de funcionamento da classe hospitalar sejam o estímulo à aquisição de habilidades e competências linguísticas e lógicomatemáticas, o espaço permite ao educador desenvolver outras atividades, entre as quais aquelas voltadas para a educação em saúde, não apenas com as crianças e os adolescentes internados, mas também com os seus familiares, podendo tornar-se um elemento motivador para a adoção de atitudes 
conducentes à saúde. Procura-se superar assim a lógica de compartimentar os conhecimentos, tornando possíveis os diversos modos de aprender, de fazer e de saber (Barros, 2007).

A introdução de conhecimentos em relação à doença que a criança está enfrentando, suas possibilidades e limitações, pode ser motivadora da adesão ao tratamento, contribuindo para um restabelecimento mais rápido e, consequentemente, para a redução do tempo de internação.

O trabalho desenvolvido, com a participação dos autores, em um hospital público de São Paulo permitiu observar que quando as crianças adquirem conhecimentos e orientações adequadas sobre a sua doença, a adesão às recomendações é maior e a reincidência do agravo é reduzida.

No entanto, percebe-se um despreparo tanto por parte dos profissionais da saúde quanto por parte dos profissionais da educação para o desenvolvimento de ações que devem ser complementares. Também há dificuldades para o estabelecimento de relações interpessoais que poderiam favorecer as condutas ante as crianças e os jovens hospitalizados.

Compete ao professor da classe hospitalar fazer o diagnóstico das dificuldades específicas no aprendizado do aluno, aplicar estratégias para sanar tais problemas e elaborar recomendações para os pais seguirem na volta do hospitalizado para a casa e para a escola de origem ao final da internação.

Atuar como professor em classe hospitalar significa promover o diálogo, explorar o ambiente hospitalar junto com a criança internada, perceber no educando a sua visão da vida, as suas necessidades e seus problemas e, com base neles, elaborar uma prática pedagógica adequada à sua realidade, contribuindo assim na construção de novos conhecimentos, necessários para uma ação ativa em prol do restabelecimento da saúde.

Na classe hospitalar, o educador procura estabelecer um elo entre a realidade do hospital e a vida cotidiana da criança. Esse processo contribui para a aprendizagem da criança, além de dar subsídios para a compreensão dos mecanismos de instalação da doença e incentivar a participação no processo de cura.

Não se pode conceber que o professor da classe hospitalar seja apenas um espectador dos fatos ocorridos durante a hospitalização. Ele deve ser um agente de mudanças na produção de conhecimentos e um provedor de ações pedagógicas que levem à formação de uma consciência crítica para que alunos e familiares, ao se tornarem participantes do processo educativo, comprometam-se nas decisões que envolvam a atenção à saúde tanto individual quanto coletiva, numa trajetória de constante enriquecimento pessoal.

A oportunidade de frequentar uma classe hospitalar devolve à criança o prazer do contato com o ambiente escolar, privilegiando as suas conquistas de aprendizagens e desvinculando-a, ainda que momentaneamente, das restrições que a hospitalização impõe, tornando a experiência de hospita- 
lização um acontecimento positivo ao seu crescimento e desenvolvimento (Ceccim, 1999).

A classe hospitalar se apoia em propostas educativo-escolares as quais se diferenciam das propostas de atividades lúdicas e de recreação que possam existir na instituição hospitalar. Mesmo que o lúdico seja uma estratégia do aprendizado no ambiente hospitalar, a intervenção pedagógico-educacional é mais específica, por ser individualizada, estar embasada numa regularidade e ter responsabilidade com o aprendizado formal da criança. Ou seja, é uma atividade inclusiva dos pais e das escolas de origem da criança, pois o fato de a criança frequentar a escola do hospital durante a hospitalização, além de servir à manutenção das aprendizagens escolares, é um incentivo ao retorno e à reintegração na escola de origem, após a alta hospitalar (Fonseca, 1999).

Atividades escolares realizadas durante a internação têm o poder de transformar o ambiente hospitalar, repleto de medo, distanciamento e dor, numa realidade que privilegia o diálogo, a experiência prévia de vida e o respeito à linguagem simbólica do enfermo.

A comunicação expressa pelo diálogo é ferramenta essencial da humanização nas práticas de saúde. O diálogo humaniza a relação entre os sujeitos, promovendo a aproximação e a confiança necessárias para uma abordagem mais ampla e adequada ao processo de restabelecimento da saúde. A comunicação dá a oportunidade de expressar necessidades e emoções que se manifestam diante do sofrimento. A forma como a criança compreende, aceita e colabora na recuperação da sua saúde depende muito da maneira como ela consegue lidar com os seus sentimentos em relação à hospitalização. E a classe hospitalar é um espaço permissível à liberação e ao compartilhamento de sentimentos, fazendo a criança hospitalizada sentir-se acolhida e compreendida, promovendo, assim, um ajustamento emocional que favorece a adaptação ao meio hospitalar.

A classe hospitalar deve privilegiar a reflexão sobre práticas sociais, valores e crenças; promover a autonomia dos alunos, respeitando os seus direitos de escolha e de tomada de decisões; e valorizar a sua história de vida, implementando, dessa forma, as ações de atenção integral à saúde. Além disso, ao buscar promover uma atenção mais humanizada no cuidado à saúde, evita transformar a relação profissional-usuário em um meio para a obtenção de certos fins.

O processo de humanização envolve sujeitos transformadores do modo de produzir cuidados de saúde. Humanizar é reconhecer que as práticas de cuidado são necessariamente intersubjetivas, ressaltando o que de fato é importante para a saúde integral das pessoas (Pereira, 2003). Cabe à política de humanização da saúde ser um instrumento de descentralização do poder nos cuidados à saúde, transformando-o em um poder compartilhado, sustentado 
por profissionais, usuários e gestores (Reis, Marazina e Gallo, 2004). A humanização é um processo que consiste na combinação entre a objetivação científica do processo saúde/doença e a valorização do sujeito. Para que essa integração ocorra, é fundamental o concurso ativo dos usuários.

A ação pedagógica desenvolvida no ambiente hospitalar é uma forma de atenção humanizada e integral à saúde da criança, uma ação conjunta dos setores de educação e saúde que universaliza a oportunidade de escolarização, independentemente do estado de saúde em que o indivíduo se encontre.

Cuidar da saúde não é apenas um processo de intervenção na doença; implica, principalmente, criar condições nas quais os indivíduos possam dispor de meios para a manutenção ou a recuperação do seu estado de saúde. Portanto, é fundamental que as ações em saúde não se restrinjam ao diagnóstico e ao tratamento dos agravos à saúde, mas atuem de forma intersetorial e interdisciplinar sobre os determinantes sociais da saúde (Deslandes, 2005).

Este artigo objetiva identificar os pontos de intersecção entre uma modalidade de educação especial - a classe hospitalar - e o Sistema Único de Saúde (SUS), do ponto de vista dos princípios da integralidade e da participação comunitária nas práticas de saúde humanizadas - pressupostos que a classe hospitalar tem buscado alcançar no desenvolvimento de ações com a criança e o jovem internados.

Os indivíduos, além de terem direito à igualdade de acesso à saúde e à atenção integral à saúde, têm direito à participação na sua cura. Isso implica a capacidade de definir, reconhecer e formular suas necessidades em saúde.

O modelo biomédico de característica assistencialista, centralizador e privatizante, assumido pelo sistema de saúde brasileiro até o fim da década de 1980, com demanda de recursos diagnósticos e terapêuticos de alta complexidade tecnológica e elevado custo, além de desconsiderar as necessidades essenciais da população, contribuiu para a fragmentação dos conhecimentos populares, castrando a habilidade e a autoconfiança das pessoas para enfrentarem situações de doença com autonomia e solidariedade. Nesse período, as internações tinham uma característica muito diferente. O enfoque era centrado no tratamento e recuperação da doença. Além disso, as crianças permaneciam muito tempo afastadas da família, e o contato com os familiares se restringia aos escassos períodos destinados às visitas. Tanto a criança hospitalizada quanto a sua família não tinham, na maioria das vezes, o direito de participar ativamente no restabelecimento da saúde. Não havia legislação compromissada com o direito da criança de desfrutar alguma forma de recreação ou de estar inserida em programas de educação durante a sua permanência no hospital. O médico tomava as decisões e cabia 'ao paciente' e à sua família somente seguir o que lhes era prescrito, sem qualquer discussão. 
A VIII Conferência Nacional de Saúde, realizada em março de 1986 em Brasília, conferiu pela primeira vez à população a oportunidade de participar de discussões sobre questões de saúde, considerando-a um direito fundamental e enfatizando a necessidade de reformulação do sistema, com descentralização da gestão, universalidade de acesso e controle social.

A reforma constitucional de 1988, em seu artigo 196, incorporou essa nova concepção de saúde. Isso resultou na implantação de um novo sistema de saúde, o Sistema Único de Saúde, que propunha um modelo de atenção diferente, em um ambiente de poder descentralizado, no qual se criariam as condições necessárias para que os indivíduos pudessem participar com autonomia das ações de saúde. Isso não implicava retirar do Estado a responsabilidade no dever de promover a saúde, mas conferia a ele novas competências, visando à sua atuação, de forma cooperativa, com gestores e uma diversidade de grupos locais, a fim de assegurar a inclusão social, garantindo os direitos de cidadania, a interação entre sujeitos e o direito à saúde (Kleba, 2005).

A Constituição democrática de 1988 estabeleceu a saúde como um direito de todos, cabendo ao Estado a responsabilidade de garanti-la, de forma universal e igualitária, por meio de programas sociais e econômicos dirigidos à redução do risco de adoecer. Instituído com base no princípio da universalidade - fundamental para a inclusão social -, o SUS tem procurado garantir o acesso aos serviços de promoção, proteção e recuperação da saúde para todos os cidadãos, independentemente do fato de serem ou não contribuintes. E, embora o acesso universal ainda não tenha sido totalmente implantado no país, já gerou substanciais melhorias nos indicadores de saúde brasileiros.

Além disso, ao estimular a criação e o fortalecimento dos sistemas locais de saúde, o SUS possibilitou o planejamento da atenção, buscando priorizar as reais necessidades da população e as práticas destinadas à saúde integral do indivíduo, contando sempre com a sua participação.

A integralidade da atenção à saúde proposta pelo Sistema Único de Saúde e garantida pela Carta Magna brasileira afirma uma compreensão da saúde dependente de fatores socioeconômicos, psicológicos e culturais, além dos biológicos. Pressupõe uma política ampla, intersetorial, articulada e comprometida com a vida, e da qual toda a população deve participar. Essa participação compreende a oportunidade de obter informações corretas necessárias para analisar de forma crítica as adversidades vivenciadas, na tentativa de solucioná-las em prol de resultados satisfatórios e no desempenho de um papel ativo na construção do modelo de atenção à saúde (Kleba, 2005).

Isso significa que o nível de saúde está relacionado à intensidade com que o meio proporciona às pessoas a oportunidade de enfrentar com autonomia e responsabilidade as condições adversas de vida, em vez de dependerem 
essencialmente de regras decididas por outros. A saúde, portanto, não pode ser considerada um estado, e sim um processo de luta, conquista e construção no qual o ser humano constantemente precisa tomar decisões, assumindo a responsabilidade pela sua vida.

A classe hospitalar constitui um novo espaço de escuta. É permissiva à participação de alunos e seus familiares na reflexão dos fatores relacionados ao adoecimento e à hospitalização, na tentativa de fazer emergir forças vitais para o enfrentamento das condições características da hospitalização. Visa à recuperação da saúde da criança o mais rápido possível, abreviando assim o regresso ao seu ambiente de origem.

A participação da população é viabilizada pela educação em saúde, que vai formar os indivíduos para o exercício pleno da cidadania, para a sua participação na sociedade, possibilitando a aquisição de conhecimentos e práticas corretas, culturalmente abrangentes, de modo a desenvolver a reflexão sobre a sua qualidade de vida, identificando os problemas relacionados à saúde, e as possíveis soluções, baseadas em suas reais necessidades (Philippi Junior e Pelicioni, 2002).

O desenvolvimento de atividades educativas em saúde durante a hospitalização é uma estratégia que faz que as crianças hospitalizadas e seus familiares compreendam com maior clareza o que está se passando em todo o processo de combate ao agravo que gerou a hospitalização, tornando-os participantes no passo a passo da recuperação da saúde.

A abordagem educativa deve estar sempre presente, com o objetivo de promover a saúde e prevenir as doenças; deve ser processada na comunicação e no diálogo entre os sujeitos, valorizando-se o conhecimento e a experiência prévia das pessoas. Somente motivadas e capacitadas, elas poderão incorporar novos significados, valores e atitudes que se transformarão em ações voltadas para a melhoria de sua saúde e qualidade de vida (Pelicioni e Pelicioni, 2007).

A educação só se dá mediante o estabelecimento de uma relação entre iguais que leve à reflexão sobre o seu meio concreto. Quanto maior a identidade entre o educando e o educador, maior é a possibilidade de eficácia do processo ensino-aprendizagem.

Educar não significa simplesmente adquirir e transmitir conhecimentos. É preciso que, no processo educativo, o educando seja considerado sujeito participante na elaboração do conhecimento que visa à transformação da sua realidade. Esse processo promove o fortalecimento comunitário e a atuação cidadã no exercício e aprimoramento do enfrentamento da situação em foco de uma forma justa, democrática e igualitária, em bases sustentáveis (Pelicioni, 2005).

O contexto hospitalar, além de priorizar o desenvolvimento de atividades pedagógicas da grade curricular do ano em que o aluno está inserido 
na escola de origem, pode proporcionar a oportunidade de a criança e seus familiares adquirirem novos saberes, inclusive a respeito da doença causadora da hospitalização. No entanto, é preciso ressaltar que o enfrentamento da problemática, além de ter como objetivo a construção de conhecimentos e o desenvolvimento de uma visão crítica, depende também de um sistema gestor permeável às sugestões e maleável às transformações, ou seja, de vontade política e da iniciativa do gestor da instituição hospitalar.

A incorporação de conhecimentos favorece a inclusão social e desperta uma consciência crítica que vai permitir encaminhamentos, tomada de decisões conjuntas e possíveis soluções de problemas; proporciona maior autonomia para que as pessoas possam influenciar e atuar sobre os determinantes de saúde; favorece a participação comunitária ativa nas decisões relativas às políticas públicas; influencia na alocação de recursos e no estabelecimento de prioridades dos serviços, baseados no princípio da equidade.

A intersecção entre o setor de saúde e a educação se faz por meio das práticas de educação em saúde, utilizadas não apenas na educação continuada dos profissionais de saúde e da educação, como também para a população em geral. O processo de ensino-aprendizagem deve sempre partir do que as pessoas percebem como algo realmente importante, valorizando-se o conhecimento prévio que elas têm sobre o assunto a ser abordado.

O conhecimento sobre a população com que se vai trabalhar, sobre suas necessidades e interesses é imprescindível para o sucesso do processo educativo e para a seleção dos métodos apropriados às diversas situações.

A educação em saúde, definida como um conjunto de saberes e práticas orientadas para a prevenção de doenças e para a promoção da saúde, representa um recurso de socialização do conhecimento cientificamente produzido no campo da saúde, mediado por equipes interdisciplinares com a intenção de promover atitudes conducentes à saúde (Czeresnia, 2003). A educação em saúde cria vínculos entre a ação técnica e o pensar e fazer cotidiano da população, permitindo um rico aprendizado dos atores envolvidos. Valorizando o respeito, a autonomia e a criatividade dos sujeitos, ela promove a capacidade de análise crítica sobre a realidade e a criação de estratégias para o enfrentamento de problemas que interferem na saúde. Assim, é um instrumento fundamental à construção da atenção à saúde integral da população.

A classe hospitalar facilita a introdução de temas novos e importantes, que devem ser discutidos utilizando-se uma linguagem acessível e compreensível, de modo a considerar os interesses do período da internação. O uso de recursos audiovisuais, livros e filmes como material didático de apoio ao desenvolvimento das atividades no hospital permite que os assuntos discutidos emerjam e facilita a elaboração dos sentimentos vivenciados pela criança. 
A Organização Mundial de Saúde (OMS) preconiza o uso de algumas estratégias de educação na chamada alfabetização em saúde. As intervenções de alfabetização em saúde também precisam ser concebidas com base nas necessidades e prioridades de saúde das comunidades, respeitando-se o seu contexto social, político e cultural - inclusive os recursos e as redes comunitárias existentes -, e com ampla participação dos indivíduos, garantindo com isto a sustentabilidade de todo o processo.

No processo de alfabetização, é necessário garantir o acesso a recursos tecnológicos facilitadores da propagação e do compartilhamento de informações básicas em saúde, de forma clara e compreensível para a população, empoderando-a para a tomada de decisões em relação às demandas de diferentes contextos de saúde, a fim de promover e manter a boa saúde durante a vida (World Health Organization, 2009).

O acompanhamento pedagógico realizado no hospital por profissionais especializados vai tornar possível, ainda, que as crianças aprendam e discutam questões relacionadas à sua doença, verificando o porquê das limitações que lhes são impostas, aprendendo a identificar sinais e sintomas de melhora e de piora, recebendo orientações para proceder corretamente em cada situação.

A construção da prática pedagógica para atuação em ambiente hospitalar deve, assim, transpor as barreiras da educação tradicional e da visão compartimentada e reducionista, promovendo o aperfeiçoamento humano como um todo, contribuindo assim para o desenvolvimento infantil e ampliando sua experiência de vida. É a partir do despertar da valorização de si própria, da liberação de seus potenciais, que a criança encontrará condições de viver com saúde, superando os momentos de tensão que a hospitalização impõe.

A prática educativa norteada pela pedagogia da problematização é a mais adequada para a educação em saúde. Instrumentalizando as crianças para a produção de trabalhos criativos, a educação com esse enfoque vai promover o desenvolvimento das suas potencialidades, em concordância com os princípios da Promoção da Saúde (Deslandes, 2005).

$\mathrm{O}$ direito da criança e do adolescente à atenção integral e a participarem do processo de recuperação de sua saúde, bem como de desfrutarem de programas de educação para a saúde e de acompanhamento do currículo escolar durante a sua hospitalização, é assegurado pela resolução ${ }^{\circ} 41$, de 13 de outubro de 1995, do Conselho Nacional dos Direitos da Criança e do Adolescente, em seus itens 8 e 9, que tratam especificamente da situação de hospitalização; no entanto, os avanços nesse sentido ainda são muito incipientes (Fórum da Reforma Sanitária Brasileira, 2006).

A OMS caracteriza como iniciativas para a promoção da saúde os programas, as políticas e as atividades planejadas e executadas de acordo com 
os princípios de intersetorialidade, empoderamento, concepção holística, participação social, equidade e sustentabilidade (Gomes, Caetano e Jorge, 2008).

A classe hospitalar, numa ação intersetorial das áreas de saúde e de educação, por meio de uma equipe multiprofissional de atenção integral, visa superar as barreiras do modelo médico tradicional, centrado exclusivamente na doença. Isso possibilitará que a criança e sua família deem um novo significado à doença e à hospitalização, empoderando-os para a participação na tomada de decisões mais apropriadas para a obtenção de melhor qualidade de vida.

As atividades da classe hospitalar ampliam a ótica da recuperação para além do combate à doença, ressaltando o apego à vida, a alegria e a criatividade, e oferecem oportunidade para que a criança, mesmo hospitalizada, possa dar continuidade à sua história de vida.

A visão integral de saúde proposta pela Promoção da Saúde se contrapõe ao modelo tecnoassistencial, marcado pela fragmentação das ações e pela hegemonia do modelo biomédico, que reduz o sujeito à objeto e o cuidado à incorporação crescente de tecnologias de alta complexidade. Assim, no âmbito da educação, a Promoção da Saúde destaca a importância de capacitar a população, por meio da implantação de programas que estimulem uma consciência crítica sobre a realidade vivida (World Health Organization, 1998).

As ações de promoção da saúde trazem no seu processo, além da sensação de cuidado, a autonomia e o desejo de vida de cada usuário do serviço de saúde. A organização de caráter interdisciplinar das ações e dos serviços de saúde, centrada no usuário e orientada por atos de escuta, atendimento e acompanhamento, amplia e potencializa a base de conhecimentos na abordagem dos determinantes da saúde, devendo melhorar a eficácia do sistema de saúde (Pelicioni, Pelicioni e Toledo, 2008).

Ao garantir as relações entre epidemiologia e ciências humanas e biomédicas, essas ações atuam nos determinantes favoráveis à saúde, e não somente nas causas da doença, contribuindo, ainda, para a elaboração de estratégias de atenção mais ricas e eficazes. A amplitude dos conhecimentos envolvidos evidencia a alta complexidade dessas ações, que contemplam o "cuidado" como uma tecnologia de saúde, consolidando a atenção integral à saúde como um dos princípios mais importantes do SUS (Ceccim e Ferla, 2006).

Ao se organizar em torno dos preceitos da Promoção da Saúde, o SUS prioriza a atenção primária, concentrando-se no usuário-cidadão como alguém que deve ser cuidado em sua integralidade (Pinheiro e Mattos, 2006).

O modelo de atenção do SUS é legitimado pelas práticas de saúde humanizadas que implicam valorização dos sujeitos, processos de gestão participativa e solidária, protagonismo dos sujeitos, ações de saúde centradas 
nas necessidades reais da saúde das populações e dos indivíduos e democratização das relações.

Na concretização do princípio da integralidade, a implantação da educação em saúde como estratégia de reorientação das práticas de saúde é fundamental. Para tal, é necessário investir na ampliação da participação e do debate sobre os determinantes sociais da saúde. Por conta dessa nova realidade, é importante o esforço dos gestores na implantação de programas na busca pela chamada humanização na saúde.

A oportunidade de frequentar uma classe hospitalar universaliza o direito à educação para todos os indivíduos independente do seu estado de saúde; descentraliza a educação no sentido de criar novos espaços no quais se possa dar continuidade ao processo pedagógico de aprendizado; amplia a atenção à saúde para além da melhor qualidade do diagnóstico e prescrição e se constitui num espaço que pode favorecer, como dito anteriormente, um processo de educação em saúde embasado na construção de conhecimentos de forma participativa e problematizadora, envolvendo o professor, aluno e os familiares acompanhantes.

O cuidado em saúde deve ir além do cumprimento dos protocolos técnicos. Deve contemplar as necessidades físicas, psicológicas e pedagógicoeducacionais. Isto significa compreender a criança como sujeito de direito, inclusive o direito à escolarização durante a hospitalização.

A ação conjunta entre os setores saúde e educação, possibilita a vinculação da classe hospitalar ao sistema educacional, na modalidade de educação especial, garantindo o desenvolvimento pleno, a construção de conhecimentos, a capacitação e o desenvolvimento de habilidades durante a hospitalização, que podem transformar, de forma positiva, a vida da criança e do adolescente, vinculando-se ao sistema de saúde como uma das modalidades de atenção integral à saúde.

A atuação de diferentes profissionais, com diferentes saberes, na atenção à criança hospitalizada é uma condição indispensável à sua recuperação. Essa forma de trabalho, além de diferenciar o cuidado, promove a renovação constante dos sujeitos envolvidos na recuperação, ou seja, da criança doente, dos familiares e dos profissionais da saúde e educação.

Atividades de educação em saúde desenvolvidas na classe hospitalar durante a hospitalização, valorizando o conhecimento prévio do aluno e de seus familiares, numa tentativa de alfabetização em saúde, contribuem no empoderamento necessário para vencer as barreiras que se impõem à participação mais efetiva visando à obtenção de um bom nível de saúde e de qualidade de vida.

No Brasil, apesar das leis e declarações que colocam a saúde e a educação como prioridade para a promoção da vida, esses direitos estão longe de ser uma realidade, principalmente para a população mais pobre. Embora 
a legislação reconheça o direito da criança e do adolescente de receberem atendimento pedagógico durante a hospitalização, a maioria dos hospitais destinados a esse público não dispõem de espaços para a atividade, o que acaba gerando mais desigualdade, tanto na educação quanto na saúde, impossibilitando a cidadania plena.

É preciso que os gestores se conscientizem da necessidade de implantação de estratégias de inclusão que facilitem a instalação e a sustentabilidade da atividade da classe hospitalar, de modo que as crianças e os adolescentes possam permanecer inseridos ao sistema educacional mesmo durante a hospitalização.

O SUS, em seus princípios, permite e estimula o desenvolvimento, nos hospitais, de atividades pedagógico-educacionais que possibilitam uma atenção à saúde integral da criança ou adolescente hospitalizados.

Sendo a classe hospitalar uma atividade que contribui para a legitimação e o fortalecimento das diretrizes constitucionais do SUS como sistema de saúde integral, participativo e pautado na humanização das práticas de saúde, tornam-se cada vez mais urgente e imprescindível o investimento e a viabilização dessa ideia por todo o país, a fim de que cada vez um número maior de crianças doentes possa ser por ela beneficiada, atendendo à concepção de integralidade na atenção à saúde.

\section{Colaboradores}

$\mathrm{O}$ autor Edson Vanderlei Zombini concebeu o estudo em termos teóricos e metodológicos, analisou os dados da literatura, elaborou a discussão e redigiu o texto. A autora Maria Cecília Focesi Pelicioni participou na análise dos dados da literatura, na discussão e na redação do texto. A autora Isabel Maria Teixeira Bicudo Pereira participou na análise dos dados. A autora Claudia Maria Bógus colaborou na análise dos dados. 


\section{Notas}

1 Médico pediatra do Hospital Infantil Cândido Fontoura da Secretaria Estadual da Saúde de São Paulo, São Paulo, SP, Brasil. Mestre em Saúde Pública pela Faculdade de Saúde Pública da Universidade de São Paulo (USP) e doutorando na Faculdade de Saúde Pública da Universidade de São Paulo (USP). <edsonzombini@ig.com.br>

Correspondência: Rua Bagé, 97, apto. 83, Vila Mariana, São Paulo, SP, Brasil, CEP 04012-140.

2 Professora associada do Departamento de Prática de Saúde Pública, Faculdade de Saúde Pública, Universidade de São Paulo (USP), São Paulo, SP, Brasil. Livre-docência pela Universidade de São Paulo (USP). <claudiab@usp.br>

3 Professora do Departamento de Prática de Saúde Pública, Faculdade de Saúde Pública, Universidade de São Paulo, São Paulo, SP, Brasil. Doutora em Saúde Pública pela Universidade de São Paulo. <claianny@usp.br>

4 Professora associada do Departamento de Prática de Saúde Pública, Faculdade de Saúde Pública, Universidade de São Paulo (USP), São Paulo, SP, Brasil. Livre-docência pela Universidade de São Paulo (USP). <ceciliapelicioni@uol.com.br>

\section{Referências}

BARROS, Alessandra S. S. Contribuições da educação profissional em saúde à formação para o trabalho em classes hospitalares. Cadernos Cedes, Campinas, v. 27, n. 73, p. 257-278, 2007.

BRASIL. Ministério da Educação e Cultura. Conselho Nacional de Educação. Diretrizes Nacionais para a Educação Especial na Educação Básica. Brasília, DF, 2001. Disponível em: <http://portal.mec.gov.br/arquivos/pdf/ resolucao2.pdf>. Acesso em: 14 fev. 2012.

. Secretaria Executiva. Núcleo Técnico da Política Nacional de Humanização. Política Nacional de Humanização - PNH: humanização da atenção e da gestão em saúde do Sistema Único de Saúde - SUS. Brasília: Ministério da Saúde, 2004. Disponível em: <http://bvsms.saude.gov.br/ bvs/publicacoes/humanizasus2004.pdf $>$. Acesso em: 3 out. 2008.
CECCIM, Ricardo B. Classe hospitalar: encontros da educação e da saúde no ambiente hospitalar. Pátio Revista Pedagógica, Porto Alegre, v. 3, n. 10, p. 41-44, 1999.

CECCIM, Ricardo B.; FERLA, Alcindo. A. Linha de cuidado: a imagem da mandala na gestão em rede de práticas cuidadoras para uma outra educação dos profissionais de saúde. In: PINHEIRO, Roseni; MATTOS, Ruben A. (Org.). Gestão em redes: práticas de avaliação, formação e participação na saúde. Rio de Ja-neiro: Cepesc, 2006. p. 165-184.

CZERESNIA, Dina. O conceito de saúde e a diferença entre prevenção e promoção. In: CZERESNIA, Dina; FREITAS, Carlos M. (Org.). Promoção da saúde: conceitos, reflexões, tendências. Rio de Janeiro: Editora Fiocruz, 2003. p. 39-53.

DE PAULA, Ercília M. A. T.; MATOS, Elizete L. M. Educação da criança hospitalizada: 
as várias faces da pedagogia no contexto hospitalar. Cadernos Cedes, Campinas, v. 27, n. 73, p. 253-255, 2007.

DESLANDES, Sueli F. O projeto ético-político da humanização: conceitos, métodos e identidade. Interface - Comunicação, Saúde, Educação, Botucatu, v. 9, n. 17, p. 401-403, 2005.

FONSECA, Eneida S. A situação brasileira do atendimento pedagógico-educacional hospitalar. Educação e Pesquisa, São Paulo, v. 25, n. 1, p. 117-129, 1999.

Atendimento escolar no ambiente hospitalar. São Paulo: Memmom, 2003. p. 7-10.

FÓRUM DA REFORMA SANITÁRIA BRASILEIRA. O SUS pra valer: universal, humanizado e de qualidade. Rio de Janeiro: Abrasco; Cebes; Abres; Rede Unida; Ampasa, 2006. Disponível em: <www.abrasco.org.br/ publicacoes/arquivos/20070306142552.pdf $>$. Acesso em: 8 fev. 2012.

GOMES, Ilvana L. V.; CAETANO, Rosângela; JORGE, Maria Salete B. A criança e seus direitos na família e na sociedade: uma cartografia das leis e resoluções. Revista Brasileira de Enfermagem, Brasília, v. 61, n. 1, p. 61-65, 2008.

KLEBA, Maria Elisabeth. Descentralização do sistema de saúde no Brasil. Chapecó: Argos, 2005.

MONTEIRO, Maria do Céu L. R. Humanização nos hospitais: gente cuidando de gente. In: AROSA, Armando C.; SCHILKE, Ana L. (org.). A escola no hospital. Campinas: Intertexto, 2007. p. 15-21.

PELICIONI, Andréa. F. Desvelando representações e práticas sociais em educação infantil. São Paulo: Senac, 2005. p.163-80.

PELICIONI, Maria Cecília F.; PELICIONI, Andréa F. Educação e promoção da saúde: uma retrospectiva histórica. O Mundo da Saúde, São Paulo, v. 31, n. 3, p. 320-328, 2007.
PELICIONI, Maria Cecília F.; PELICIONI, Andréa F.; TOLEDO, Renata. F. A educação e a comunicação para a promoção da saúde. In: ROCHA, Aristides. A. (Org.). Saúde pública. São Paulo: Atheneu, 2008. p. 165-177.

PEREIRA, Adriana L. F. As tendências pedagógicas e a prática educativa nas ciências da saúde. Cadernos de Saúde Pública, Rio de Janeiro, v. 19, n. 5, p.1.527-1.534, 2003.

PHILIPPI JUNIOR, Arlindo.; PELICIONI, Maria Cecília F. Alguns pressupostos da educação ambiental. In:

(Orgs.). Educação ambiental: desenvolvimento de cursos e projetos. São Paulo: Signus, 2002. p. 3-5.

PINHEIRO, Roseni; MATTOS, Ruben A. Implicações da integralidade na gestão da saúde. In: PINHEIRO, Roseni; MATTOS, Ruben A. (Orgs.). Gestão em redes: práticas de avaliação, formação e participação na saúde. Rio de Janeiro: Cepesc, 2006. p. 11-26.

REIS, Alberto O. A.; MARAZINA, Isabel V.; GALLO, Paulo R. A humanização na saúde como instância libertadora. Saúde e Sociedade, São Paulo, v. 13, n. 3, p. 36-43, 2004.

SOCIEDADE BRASILEIRA DE PEDIATRIA. Os 10 passos para a atenção humanizada à criança e ao adolescente. Rio de Janeiro: Sociedade Brasileira de Pediatria, 2001. Disponível em: <www.sbp.com.br/show_ item2.cfm?id_categoria=65\&id_detalhe= 1877\&tipo_detalhe=s $>$. Acesso em: $27 \mathrm{dez}$. 2009.

WORLD HEALTH ORGANIZATION. Health promotion evaluation: recommendations to policymakers. Copenhagen: European Working Group on Health Promotion Evaluation, 1998. Disponível em: <http:// whqlibdoc.who.int/euro/1998-99/EUR_ICP_ IVST_05_01_03.pdf. Acesso em: $27 \mathrm{dez}$. 2009.

Health Literacy and Health Promotion. In: Global Conference on Health Promotion, 7. Proceedings... Nairobi, 26-30 
Oct. 2009. Disponível em: <www.who.int/ healthpromotion/conferences/7gchp/ documents/en/index.html. Acesso em: 20 jun. 2010 .

Recebido em 27/10/2011

Aprovado em 09/02/2012 